\title{
Integration Of Sustainability Principles Into Project Baselines Using A Comprehensive Indicator Set
}

Jude Talbot, AMEC, Canada

Ray Venkataraman, Penn State Erie, USA

\begin{abstract}
Sustainability is defined as balancing the three concepts of people, planet, and profit to maximize the absolute value of an undertaking. Therefore it deals with the long term economic, social, and environmental effects of an undertaking. However, the definition of sustainability, which is focused on the long term, does not provide practical guidance to companies attempting to integrate sustainability into their projects, which by definition are temporary constructs. The imbalance between the definition of sustainability and the definition of a project has made it difficult to incorporate meaningful sustainability indicators into project baselines.

In this paper we propose a framework for integrating sustainability into project baselines for consulting engineering projects in the industrial and resource extraction fields. This framework is based on using a sustainability indicator set that has been derived from existing sets applicable to industrial or resource extraction projects. The utility of the proposed framework and indicator set are back checked against a recently completed engineer, procure, and construction manage mining project undertaken by a large engineering and project management services organization.
\end{abstract}

Keywords: Sustainability; Project Management; Project Baseline

\section{INTRODUCTION}

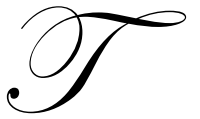

he modern concept of sustainability was originally defined at the World Commission on Economic Development in 1987, often known as the Brundtland Commission[1]. At the most basic level, sustainability is balancing the three concepts of people, planet, and profit to maximize the absolute value of an undertaking. Using this concept, sustainability has been embraced at the corporate level in many corporations. However, this definition does not provide practical guidance to companies attempting to integrate sustainability into their projects, which are by definition temporary undertakings that have a specific objective and a definite beginning and end, with the objective mostly related to the creation of a unique product or service[2] because this definition of sustainability deals with the long term economic, social, and environmental effects of an undertaking.

A few organizations have driven sustainability deep into their organizations by including specific sustainability targets in their projects, such as new facility construction or new product design. However, these targets are usually internally set so are very specific to the needs, culture, and market situation of each company. Internationally, few large consulting engineering companies are able to offer their clients a range of sustainability services within their project execution philosophies that are backed up by procedures, indicators, and methodologies.

In this paper we examine one large engineering and project management services organization that is a world leader among their peers in sustainability. This organization has many large extractive resource companies and government agencies as clients, which are some of the most advanced organizations in the sustainability field and demand high levels of sustainability acumen from their consultants. This organization also has clients that are 
looking to their consultants to show them the way in the field of sustainability. In this situation, there is an opportunity to be an early mover in driving sustainability into the organization's project execution, which would allow the firm to differentiate itself from its competitors, both reputationally and materially when bidding for work. While the Global Reporting Initiative (GRI) is the global standard for corporate sustainability reports [3, 4], there is no standardized method of measuring sustainability on consulting engineering projects in the resource extraction and manufacturing industries and therefore, there are no standardized sets of sustainability indicators, accounting practices, and measurement tools available for consultant companies to use.

This paper proposes an indicator set for use by consulting engineers and their clients on their projects. The indicator set is based on existing indicator sets that are applicable to industrial or resource extraction projects; those used by the International Federation of Consulting Engineers (FIDIC), the Global Reporting Initiative (G3), the US Green Building Council (LEED), the International Finance Corporation (IFC), the Ceres and Tellus Institute (FRP), and the Mining Association of Canada (TSM)[5]. The paper evaluates the indicator set against a recently completed consulting Engineering, Procurement, Construction Management (EPCM) mining project. The goal of this paper is to help standardize the sustainability process, making it easier to implement and more mainstream.

\section{2}

\section{LITERATURE REVIEW}

Practical tools, which systematically include sustainability within the evaluation process, are needed to align project management methodologies with the principles of sustainable development[6]. There is also a definite need to develop indicators that can be used in decision-making processes to ensure that projects are managed according to practices that will contribute to sustainable development[7].

Most literature on sustainability indicators in corporations has focused on securing high level corporate support to measure sustainability indicators' effectiveness or on how corporate entities can produce meaningful sustainability reports to their stakeholders. Relatively little research has been carried out into the sustainability frameworks, including indicators and indicator indices, required by consultants in industrial resource extraction projects to benchmark performance against sustainability principles.

\subsection{Sustainability Indicator Frameworks and Accounting}

Koo and Ariaratnam (2008) provide a four step framework for selecting sustainability indicators for projects[8]. They focus on a water main replacement project but their findings are generally applicable for industrial and resource extraction projects. The steps are:

1. Define the project details

2. Determine the spatial and temporal project boundaries

3. Identify the indicators (using existing indicator lists as a basis)

4. Analyze the indicator attributes for assessment

Casella Stanger, Forum for the Future, and Carillion plc[9] provide a framework for step four of this framework. The framework is presented for construction projects but is applicable for industrial and resource extraction projects. The framework involves the following steps:

1. Categorizing the indicators into economic, environmental, and social categories.

2. Creating sub categories for direct, internal to the organization, and indirect, external to the organization, accounts within each of the categories in step one.

3. Determine what information is already collected via traditional project accounting methods and what additional information requires collection.

\subsection{Sustainability in Project Management in the Resource Sector}

Labuschagne, Brent, and van Erck[4] provide a framework for organizing indicator sets into categories that can be used to evaluate sustainability at the operational level in process industries. They[4] start with the basic three 
aspects of sustainability: economic, environmental, and social, and then break them into sub categories that contain groups of indicators. The framework is shown in Figure 1.

A multi-level hierarchy is used, with variations, by all of the indicator sets examined in this paper. However, all of the indicator sets examined contained too many indicators at the lowest level and as a result are very complex to track at the project level. This is seen as a leading cause of poor uptake of the indicator sets at the project level within organizations. Labuschagne, Brent, and van Erck[4] help solve this problem by identifying inter-related groups of indicators in Level 4 making it possible to find a limited set of trackable data that enables judgement of achievement for each of the relevant items in Level 4. This paper proposes a framework for consultants on natural resource extraction and industrial projects that is similar levels 3 and 4 from Figure 1.

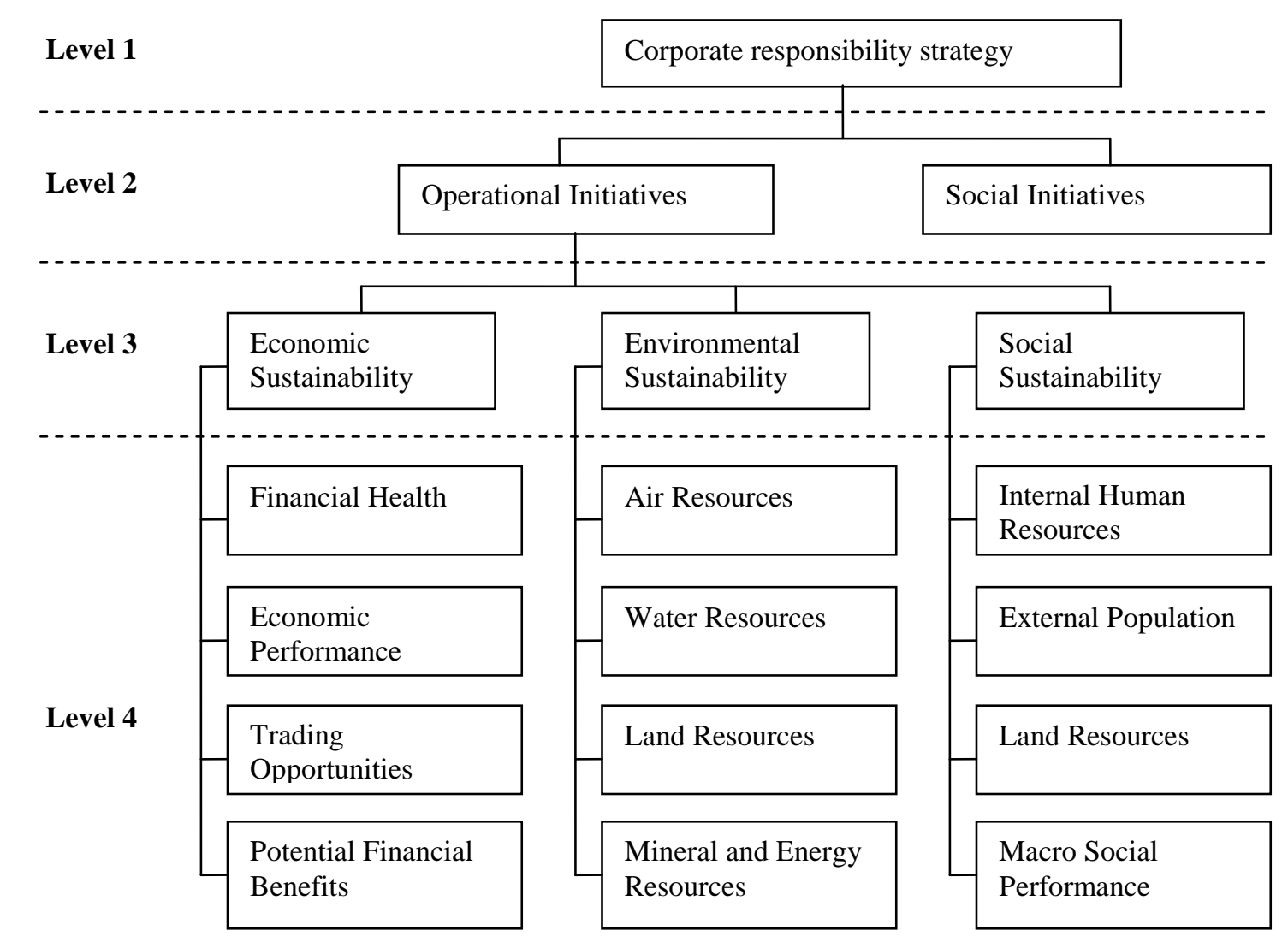

Figure 1: Levels 1-4 of the proposed operational sustainability framework

Source: Labuschagne, C., Brent, A.C., van Erck Ron P.G., Assessing performance of industries.

University of Petroria openUP, 2007.

\section{FRAMEWORK FOR INTEGRATING SUSTAINABILITY} industries.

This paper reviewed six indicator sets that are relevant to the natural resources extraction and industrial

\subsection{Global Reporting Initiative - G3 Reporting Guidelines}

The Global Reporting Initiative (GRI) was created by the United Nations Environment Programme together with the NGO, Coalition for Environmentally responsible Economics (Ceres)[10]. The guideline contains in excess of 100 indicators split into the standard three groups of economic, social, and environmental dimensions and then 
further split into different aspects. Figure 2 outlines the hierarchical nature of the GRI.

The three key strengths of the GRI indicator set are:

- $\quad$ its acceptance as the world standard for corporate sustainability standards,

- $\quad$ reporting against the GRI indicators at a project level will often produce alignment between project and corporate sustainability indicators, and

- $\quad$ its reporting guideline documentation provides some guidance to what level the indicators should be considered at i.e. project, operational, corporate.

Two key weaknesses of the GRI indicator set are:

- $\quad$ some of the indicators are very difficult to report against and

- $\quad$ the guidance provided in the GRI reporting guidelines is very general.

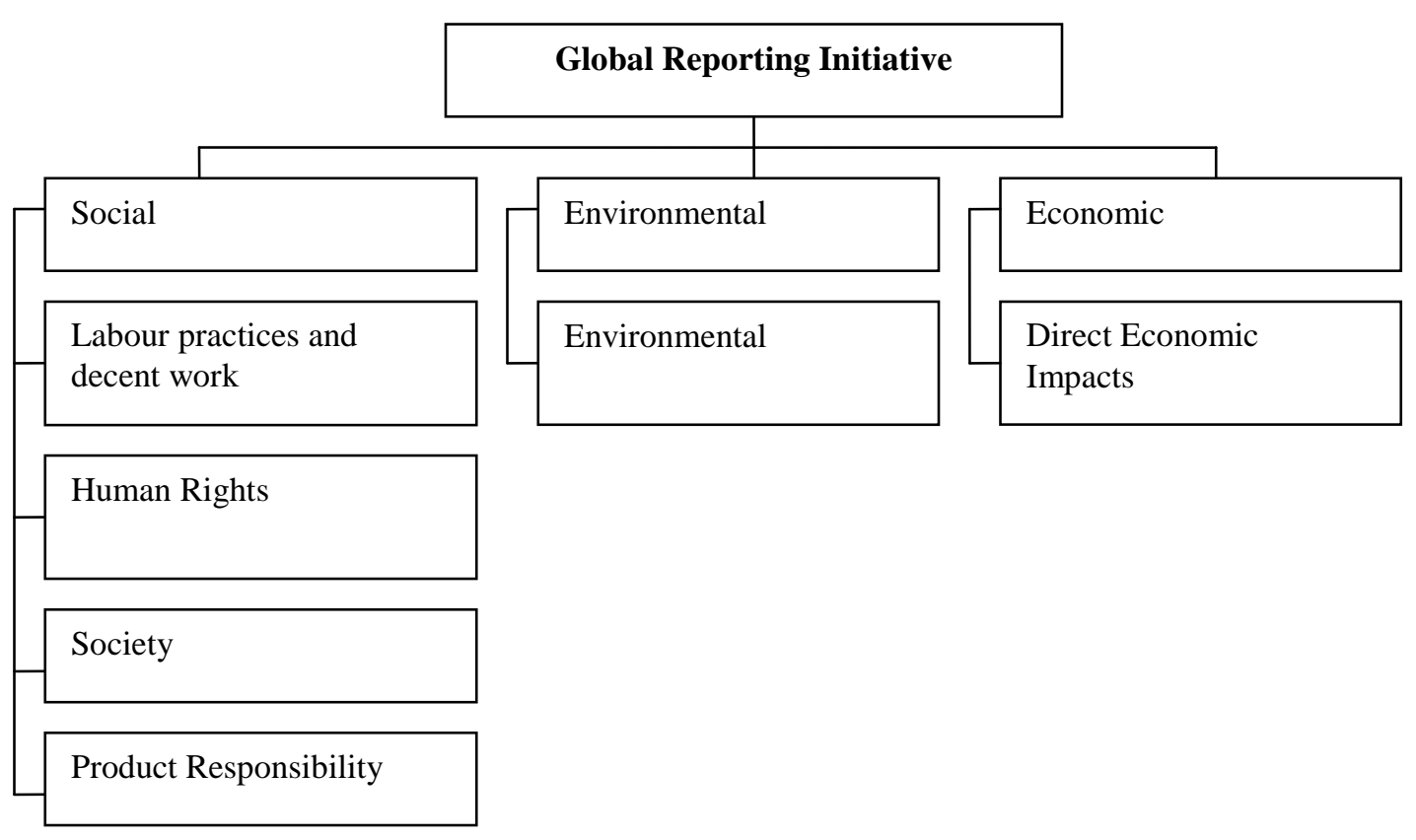

Figure 2: The hierarchical structure of the GRI framework

Source: Labuschagne, C., Brent, A.C., van Erck Ron P.G., Assessing performance of industries.

University of Petroria openUP, 2007.

\subsection{Ceres and the Tellus Institute - Facilities Reporting Project}

In 2003, Ceres and the Tellus Institute launched the Facility Reporting Project (FRP) as a multi-stakeholder effort to develop consistent, comparable, and credible economic, environmental and social reporting guidance for individual facilities in the United States[11]. The FRP indicators and guidance mirror the GRI, so that each facility within an organization could report against the FRP, assisting the overall corporate entity to report against the GRI. Therefore the FRP has essentially the same strengths and weaknesses as the GRI. 


\subsection{International Finance Corporation - Performance Standards for Social and Environmental Sustainability}

The IFC is an institution within the World Bank Group. The IFC environmental and social standards performance standards exist to minimize a project's negative impact on the environment and on affected communities. There are eight performance standards: Social and Environmental Assessment and Management System, Labour and Working Conditions, Pollution Prevention and Abatement, Community Health, Safety and Security, Land Acquisition and Involuntary Resettlement, Biodiversity Conservation and Sustainable Natural Resource Management, Indigenous Peoples, and Cultural Heritage.

Two key strengths of the IFC Performance Standards are:

- they are thorough and clearly outline the requirements of the management framework needed to achieve the standards, and

- $\quad$ from the perspective of this paper, they are specifically designed for the large industrial and resource extraction type projects.

Two key weaknesses of the IFC Performance Standards are:

- $\quad$ there are no suggested tracking measures for the guidelines in the guidance, and

- $\quad$ the wording of the guidelines makes it difficult to track achievement.

\subsection{International Federation of Consulting Engineers - Project Sustainability Management Guidelines}

FIDIC has published a Project Sustainability Management (PSM) process, indicator set, and guidance as the basis for the development of a system to integrate sustainability into projects. In the PSM process, the owner's project vision is balanced against cost and available alternatives, by selecting appropriate project goals and indicators for sustainable development. Objectives for sustainable development are therefore addressed in much the same way as other project objectives are addressed in the project's quality plan[12].

Two key strengths of the FIDIC PSM guidelines are:

- the indicator system is designed to prevent the project focussing on one area of sustainability while neglecting other areas.

- $\quad$ FIDIC bases their framework on integrating sustainability into the project management processes and ensuring, where possible, that each of the indicators has a measurable success criteria associated with it.

Two key weaknesses of the FIDIC PSM guidelines are:

- $\quad$ Many of the success criteria provided are difficult to measure at the project level.

- $\quad$ Many indicators are difficult to track or only appropriate for the largest projects.

\subsection{Towards Sustainable Mining - Performance Indicators}

The Mining Association of Canada has launched the TSM indicator set that is explicitly geared towards issues within the mining industry. This paper includes these indicators to explore how useful industry specific indicator sets are in creating general indicator sets. For the most part, it was found these indicators were already part of other indicator sets or were not generally applicable. 


\subsection{Green Building Council - Leadership in Energy and Environmental Design Indicators}

The LEED indicator set is a green building rating system for occupied buildings. It is not generally applicable to industrial or natural resource extraction projects. However, LEED is the most commonly known indicator set within the general public and is often referred to first by clients. Many of the specific indicators within LEED are generally applicable.

\subsection{Sustainability Within the Corporate Organization Examined}

As shown in Figure 3, the organization examined treats sustainability as the combination of economic effectiveness, social justice and environmental protection, the three sustainability pillars.

The state of a project may be represented anywhere on Figure 3. "A first order state occurs when the project state is such that it sits within only one circle. A second order state occurs when the project sits within the overlap of two circles, and a third order state occurs when the project sits within the centre overlap of all three circles. Traditionally, projects have often explored single state sustainability within the economic dimension while the third order is rarely achieved by projects... because of difficulties achieving sustainability in the people dimension[14] where there are more subjective factors for consideration.

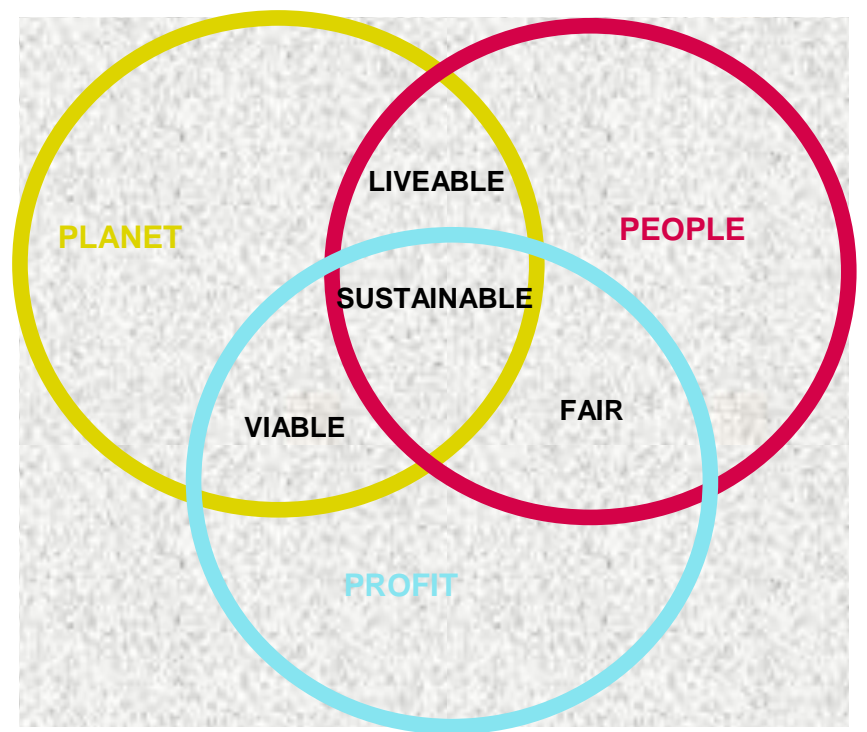

Figure 3: Three Strands of Sustainability at the Organization Examined

Source: Organization Examined Sustainability Management Overview (2009), http://www.[Organization_Examined_Intranet].com/docs/fn/Sust/Sustainability_management_American_English_pdf.

These concepts lead to the organization's expression of their sustainability programme, which is integrating social and environmental concerns into business making decisions and operations and into stakeholder interactions. The programme focuses on:

- $\quad$ People: Employment Rights, Human Rights, Ethics, Health and Safety, and Community

- $\quad$ Planet: Environment

- $\quad$ Profit: Profitable Growth

Each focus area has a goal statement for the organization to follow. An example is for safety "Providing a healthy and safe working environment is of paramount importance to the organization and its stakeholders and we do this through maintaining a world class safety culture[13]." 
Responsibility for sustainability originates at the board level with the Chief Executive Officer who also retains the title of Chairman of the Sustainability Programme. Implementation of the sustainability programme throughout the organization is driven from the corporate level by the Sustainability Programme Manager who works with and directs divisional teams that contain local representation in each office/area where the organization operates. The structure of the divisional sustainability teams is designed by the division to fit their unique needs.

\section{SUSTAINABILITY INDICATOR SET SELECTION}

The criteria for selecting indicators from the pre-existing indicator sets for inclusion in this paper's indicator set were that the indicators were:

- $\quad$ measurable in a project setting,

- $\quad$ likely to be impacted by an industrial or natural resources extraction project,

- $\quad$ applicable to a wide range of industrial or natural resources extraction industries.

The most clearly written and easiest to track in a consulting project indicator was used in case of duplication. The indicators were not filtered for the project types the consultant would likely encounter in their portfolio to make the list as broad as possible.

\subsection{Economic Indicators}

For the dimension of economic sustainability, all indicators were 'external facing' meaning that the indicators focus on the economic impact of the project on external stakeholders. This was done because the internal facing economic component of project performance is already well defined and because the evaluation of performance in the area of community capital is of utmost importance in evaluating the social sustainability of a project as it...can directly influence stakeholder participation initiatives.[4]

\subsection{Environmental Indicators}

Environmental sustainability is well defined and all indicator sets have indicators that relate to this dimension. The challenge for this dimension was determining which indicators reasonably applied to consultants for resource extraction or industrial projects.

\subsection{Social Indicators}

Little work has been carried out on social sustainability as it applies to business[15]. Thus there is a lack of consensus about what social sustainability is or should be on projects and a multitude of social sustainability indicators exist, each with a different focus.

For this paper, social business sustainability is both internally and externally focused. The internal focus concerns the health and well being of employees, disciplinary practices, equity and human rights in employee sourcing, and training and development opportunities for employees. The external focus concerns the impact of the project on...local, regional, and national communities, as applicable.[4]

\subsection{Indicator Organization}

Approximately 275 unique indicators were found that could apply to consulting projects in natural resource extraction and industrial settings, which are too many to be tracked and would hinder the uptake of sustainability implementation and measurement on projects. Therefore the set was organized into high level sustainability themes, each encompassing specific indicators, which allows for easier sorting and tracking. In the interest of brevity, the list of sustainability themes and the associated indicators are not provided in this paper. 


\section{HOW TO USE THE INDICATORS}

\subsection{Stakeholders}

In all dimensions of sustainability, it is important for a project to define [its] stakeholders. The treating of stakeholders in an ethically and socially responsible manner has been seen as the core of CSR[16]. Additionally, stakeholder management has been regarded as the tool to connect strategy to social and ethical issues[17]. Without defining project stakeholders and a thorough understanding of their wants and needs, it is not possible to come up with a comprehensive set of sustainability indicators for that project. Methodology for selecting project stakeholders is covered elsewhere including in Winch 2004[18] and not further discussed in this paper.

\subsection{Assigning Indicator Ownership}

Consulting engineers rarely own or operate the assets that they develop, unless under a separate contract. It is even rarer that they are associated with the marketing, handling, and development, of the products that are developed However, it is....the asset life cycle resulting from the project, and the subsequent product life cycle resulting from the asset that have economic, social, and environmental consequences, which are in turn associated with an implemented project[2]. Therefore each indicator selected for the project's sustainability indicator set must include information on where in the project lifecycle the indicator can be achieved, where it can be measured, and who has the ability/responsibility for meeting the indicator's measurement criteria. An industrial or natural resources extraction project can generally be separated into seven generic phases as outlined in Table 1.

Table 1: Life Cycle Phases in a Project

\begin{tabular}{|c|c|}
\hline Phase Name & Description of Phase \\
\hline $\begin{array}{l}\text { Idea Generation / } \\
\text { Definition }\end{array}$ & $\begin{array}{l}\text { In this phase the idea for a new project is generated and the initial proposal that describes the } \\
\text { business need must be prepared. This phase does not require a formal project plan. }\end{array}$ \\
\hline Pre-Feasibility & $\begin{array}{l}\text { The goal of this phase is to evaluate the existing proposal in terms of financial, operational, and } \\
\text { technical viability as well as against the company's strategy. Overlapping or synergy with other } \\
\text { projects should also be checked out. }\end{array}$ \\
\hline Feasibility & $\begin{array}{l}\text { The optimum solution to address the business need must be identified and defined. All areas of the } \\
\text { solution must be analyzed and assessed to determine killer concerns and risks. }\end{array}$ \\
\hline $\begin{array}{l}\text { Development and } \\
\text { Execution / Engineering } \\
\text { and Construction }\end{array}$ & $\begin{array}{l}\text { This phase involves design, development, creation, and building of the chosen solution. The } \\
\text { supporting system manuals, business processes, and training for the solution must also be developed } \\
\text { during this phase. }\end{array}$ \\
\hline Commissioning & $\begin{array}{l}\text { In this phase the solution is tested in an operational environment. The purpose is to validate the } \\
\text { acceptance and capabilities of the solution. }\end{array}$ \\
\hline Launch / Start Up & $\begin{array}{l}\text { The project is handed over to the business units (or customer) and thus released to the operational } \\
\text { environment during this phase. This phase also marks the beginning of operational support. }\end{array}$ \\
\hline $\begin{array}{l}\text { Post Implementation } \\
\text { Review / Project } \\
\text { Follow-Up Review }\end{array}$ & $\begin{array}{l}\text { After sufficient time ( } 9-15 \text { months), the project should be assessed to determine if the benefits were } \\
\text { delivered and what the impact of the project was on the business. Lessons learned should be } \\
\text { captured for future reference. }\end{array}$ \\
\hline
\end{tabular}

Source: Buttirck, R., The project workout: a toolkit for reaping the rewards from all your business projects. 2000, London: Prentice Hall.

\subsection{Example of Indicators with Ownership}

An example of how the indicators would be organized in a project setting is given in Figure 4. 


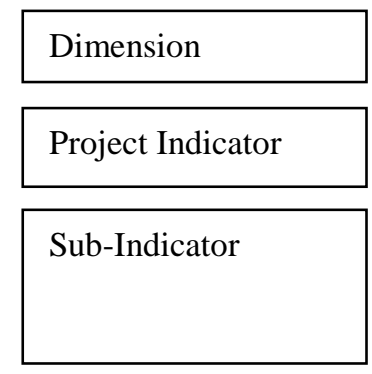

Owner

Project Lifecycle

Phase for

Measurement
Social

Maintain human rights standards

Percentage of security personnel trained in the organization's policies or procedures concerning aspects of human rights that are relevant to operations.

Consultant or owner, depending on who owns the security contract.

Every stage where security is present, likely from the engineering stage onwards.

Figure 4: Example Sustainability Indicators with responsibility assigned and lifecycle stage for measurement identified

BACK CHECKING THE PROJECT INDICATOR SET AGAINST A RECENTLY COMPLETED EPCM PROJECT

The indicator set was reviewed against a recently completed mining project using feedback from the consulting engineer's project manager and key staff engaged in preparing the project's environmental impact assessment. The feedback was gathered by reviewing the high level project indicators in an interview format. The responses to the interview questions were then collated and compared with the possible sub-indicators that could have related to the project. A clarification interview was also conducted.

This project was located in a remote location in northern Canada. The mine was built on a greenfield wilderness site. This site was pristine and there were no past or present communities nearby so there were no items of cultural heritage to define or protect on the site. However, the land was part of the traditional hunting ground of the indigenous peoples of North America and was located within the caribou's annual migratory route. Many indicators in the high level indicator list applied to the project, although consulting engineer did not have responsibility for all of them. It was felt that all the indicators including those that did not apply to this project could be the responsibility of the engineer on other projects.

\subsection{High Level Project Indicator Review - Social}

There was relatively little emphasis required on the social aspects of this project because it was executed in the developed world (Canada), it took place in one of the few places in the world with no people living there and no history of settlement, and it was self funded by the client and did not involve funding from the IFC or Equator Principle banks. Under different conditions, the social indicators would have been much more prominent.

Responsibility for the high level social indicators was as follows.

- The consulting engineer was responsible for the indicator 'Take responsibility for impacts of the projects outputs (products and services)' in regards to rotation and transportation to and from site, living arrangements for employees and contractors in the camp, and pollution outputs from the mine.

- The indicators, 'maintain community health, safety, and security', 'maintain a crisis communication plan', and 'maintain human rights standards'; had joint responsibility between the consulting engineer and the client.

- The client was responsible for the indicator, 'Preserve cultural heritage' and directed the consulting engineer's actions to achieve the indicator. 
- $\quad$ The client was solely responsible for the indicators 'Maintain effective communication with local stakeholders', 'Enable positive outcomes for indigenous peoples', 'Ensure decent work and labour practices are adhered to', and 'Contribute to local / national housing and educational system'.

- $\quad$ Other social high level indicators were not applicable to this project.

\subsection{High Level Project Indicator Review - Environmental}

This project was located in one of the few areas of the world that had not been settled in human history, a truly pristine environment. Therefore, environmental concerns were paramount in all aspects of the project.

Responsibility for the high level environmental indicators was as follows.

- The consulting engineer, through their design strategy, owned and implemented the indicator 'Minimize or eliminate energy use and procure energy from renewable sources'.

- The consulting engineer also owned and implemented the indicator 'Indoor Environmental Quality occupied buildings only'.

- The majority of the indicators were owned by the client who delegated the design and implementation to the consulting engineer. These included 'Manage natural resources in a sustainable manner to promote conservation and maintain biodiversity', 'Comply with all applicable environmental regulations', 'Minimize or eliminate air emissions', 'Water pollution: discharges, effluents, and spills', 'Fresh water withdrawal and recycling', and 'Waste and hazardous waste control, minimization, or elimination'.

- One indicator 'Transportation to and from site' was only indirectly addressed in the environmental management plan.

- $\quad$ Other environmental high level indicators were not applicable to this project.

\subsection{High Level Project Indicator Review - Economic}

In many cases, including this project, the client will have the greatest stake and will own the responsibility for the economic indicators. This consulting engineer was involved in two indicators but not in control either of them. These were:

- $\quad$ 'Provide economic opportunities for the local community - supply chain' where the consulting engineer had the responsibility for the purchasing function of the project and therefore had a role in achieving the client's commitment to supply a specified amount of material from local vendors, and

- $\quad$ 'Design the project to maximize it's lifespan with a minimum level of care and maintenance' where the expected service life of the equipment was an important consideration when selecting equipment because of the remoteness of the project.

\subsection{Project Sub-Indicator Review}

For each high level project indicator that the consultant had some level of responsibility in the project, the indicator set's sub-indicators were examined to determine applicability to the project. A sub-indicator was found that could have been used to track each of the high level indicators that the consultant had some responsibility for. However, if the indicator set had been used in real time in the project, it is likely that the project stakeholders, especially the client, would have created new sub-indicators or rewritten some of the existing sub-indicators.

\section{CONCLUSIONS}

This paper addresses the imbalance between the long term nature of sustainability and the unique, finite nature of projects to make it easier to incorporate meaningful sustainability indicators into project execution plans. It specifically addresses the fact that there is no generally accepted standardized method of measuring sustainability on EPCM consulting projects in the industrial or resource extraction industries. Existing, collections of corporate sustainability indicators have been evaluated for their relevance to consulting projects in the industrial or resource 
extraction industries and for duplication between collections. The resulting combined list contains approximately 300 indicators and is too large to manage in a project setting or integrate into a project execution plan. Therefore the indicators were grouped as sub-indicators into common themes which produced a more manageable set of 27 high level indicators, not all of which will be applicable to all projects. Depending on the specific project circumstances and stakeholder requirements, one or more of the sub-indicators within each high level indicator theme can be used to measure the attainment of sustainability on the project.

This list of high level indicators and list of the relevant sub-indicators have been back checked against a recently completed EPCM mining project in a remote setting in northern Canada. While this back checking exercise is not a substitute for a rigorous statistical check, the results show that this indicator set likely needs only minor modification before being used on an actual project.

The procedure for using the indicator set in a project setting is as follows:

1. Collect information on the stakeholder requirements of the project (using methods not described in this paper).

2. Use the high level sustainability indicators to sort the collected stakeholder requirements into sustainability themes. New high level sustainability indicators will occasionally be required to cover uncommon project circumstances.

3. Determine which sustainability sub-indicators can be used to track the project's achievement of sustainability. On many projects, more than one project specific sustainability sub-indicators will be required for each high level indicator.

4. Determine the sustainability sub-indicator's owner, who will be responsible for its achievement, and where in the project's lifecycle the sub-indicator will be addressed.

5. Determine indicator success criteria for each relevant sub-indicator used on the project and what information will be collected to measure achievement of these criteria.

6. Track the project's progress against the indicator success criteria using information reported by the project.

This procedure highlights a possible area for future study, creating a list of standard sustainability sub-indicator success criteria. The unique nature of each project and of each set of client-consultant processes dictate that the success criteria list will never be complete, but building the list will highlight the types of information needed to determine the sustainability achievement and gives projects a starting point to work from. Work could then be done investigating how to integrate sustainability reporting into project reporting so that the same information could be used for multiple purposes and project sustainability management would be seen as less burdensome.

Another possible area of further research is determining the utility of this sustainability indicator list in other industries. There are likely common threads that run through all industries, especially within the high level indicators. Discovering these links and leveraging on the research performed in this paper will assist in making project sustainability management a defined and accepted aspect of project management.

The basic definition of sustainability, balancing the three concepts of people, planet, and profit to maximize the absolute value of an undertaking, is a worthy goal to strive for. However, translating this concept into concrete tools for projects and project managers to use has proven to be difficult. Hopefully this paper has helped create these tools, has brought sustainability one step closer to the mainstream of project management, and will assist project managers in doing their part to achieve a truly sustainable world.

\section{AUTHOR INFORMATION}

Jude Talbot is a project manager and sustainability champion at AMEC, an international engineering and project management services company. His current research focuses on the intersection of sustainability and project management in an effort to normalize the incorporation of sustainability on projects. He completed his masters studies at Penn State University where he earned a Master's Degree in Project Management. He is a professional engineer and a LEED accredited professional. He lives in Vancouver, Canada where he enjoys the west coast life style and the wide open wild spaces at his doorstep. E-mail: jude.talbot@amec.com 
Dr. Ray Venkataraman is a Professor of Supply Chain and Project Management at Penn State University, Erie, PA. He has a Ph. D. in Management Science from Illinois Institute of Technology and over thirty years of teaching experience. His teaching interests are in the areas of Supply Chain and Project Management. He won an award for excellence in business teaching and has several publications in top Operations Management journals and has published a book - Cost and Value Management in Projects. His current research is in Manufacturing Planning and Control Systems and Supply Chain issues in Project Management. E mail: rrv2@psu.edu

\section{REFERENCES}

1. Association of Professional Engineering and Geoscience, B.C., Part 3e: Practice Specific Module Consulting Engineering and Geoscience, in Sustainability in Professional Engineering and Geoscience: A Primer. . May 2004.

2. $\quad$ Brundtland, G.E., Our Common Future: The World Commission on Environment and Development. 1987, Oxford: Oxford University Press.

3. Buttirck, R., The project workout: a toolkit for reaping the rewards from all your business projects. 2000, London: Prentice Hall.

4. $\quad$ Canadian Business for Social Responsibility, Sustainability Indicator List, J. Talbot, Editor. 2007: Vancouver.

5. Edum-Fotwe, F.T., Price, Andrew D.F., A social ontology for appraising sustainability of construction projects and developments. Int. J. Project Manage., 2008.

6. Facilities Reporting Project (FRP) About FRP. (2007) http://www.ceres.org/Page.aspx?pid=436.

7. Gladwin, T.N., Kennelly, JJ, Krause T-S., Shifting paradigms for sustainable development: implications for management theory and research. Acad Manage Rev, 1995. 20(4): p. 874-907.

8. Global Reporting Initiative, GRI sustainability reporting guidelines. 2002: Boston (MA).

9. Hopkins, M.J.D., Sustainability in the internal operations of companies. Corporate Environmental Strategy, 2002. 9(4): p. 398-408.

10. International Federation of Consulting Engineers (FIDIC) Bookshop: FIDIC Project Sustainability Management Guidelines (2004) http://217.197.210.21/resources/contracts/describe/FI-EN-T-AA10.asp?back=/bookshop/prod_page.asp\&ProductCode=FI-EN-T-AA-10\&price=20.

11. Koo, D.-H., Ariaratnam, Samuel T., Application of a Sustainability Model for Assessing Water Main Replacement Options. Journal of Construction Engineering and Management 2008. 134(8).

12. Labuschagne, C., Brent, A.C., Sustainable Project Life Cycle Management: The need to integrate life cycles in the manufacturing sector. International Journal of Project Management, 2005. 23(2): p. 159-168.

13. Labuschagne, C., Brent, A.C., van Erck Ron P.G., Assessing performance of industries. University of Petroria open UP, 2007.

14. Organization Examined Sustainability Management Overview (2009), http://www.[Organization Examined Intranet].com/docs/fn/Sust/Sustainability_management_American_English_.pdf.

15. Stranger, C., Forum for the Future, Carillion plc, Sustainability accounting in the construction industry. Sustainability accounting in the construction business. 2002, London: Ciria publishing services.

16. Sunter, W.V.a.C., Beyond reasonable greed: why sustainable business is a much better idea. 2002, Cape Town: Human \& Rousseau Tafelberg.

17. Warhurst, A., Sustainability indicators and sustainability performance management, in Mining, Minerals and Sustainable Development. March 2003.

18. Wartick, S.L.a.W., D. J, Editors, International business and society. 1998, Malden (MA): Blackwell.

19. Winch, G.M., Managing Project Stakeholders, in The Wiley Guide to Managing Projects, W.G. Morris, Pinto Jeffrey K, Editor. 2004, John Wiley \& Sons: Hoboken, New Jersey. p. 321. 